\title{
Multiple signaling pathways in Sertoli cells: recent findings in spermatogenesis
}

\author{
Fei-Da Ni ${ }^{1}$, Shuang-Li Hao ${ }^{1}$ and Wan-Xi Yang (1) ${ }^{1}$
}

\begin{abstract}
The functions of Sertoli cells in spermatogenesis have attracted much more attention recently. Normal spermatogenesis depends on Sertoli cells, mainly due to their influence on nutrient supply, maintenance of cell junctions, and support for germ cells' mitosis and meiosis. Accumulating evidence in the past decade has highlighted the dominant functions of the MAPK, AMPK, and TGF- $\beta /$ Smad signaling pathways during spermatogenesis. Among these pathways, the MAPK signaling pathway regulates dynamics of tight junctions and adherens junctions, proliferation and meiosis of germ cells, proliferation and lactate production of Sertoli cells; the AMPK and the TGF- $\beta$ / Smad signaling pathways both affect dynamics of tight junctions and adherens junctions, as well as the proliferation of Sertoli cells. The AMPK signaling pathway also regulates lactate supply. These signaling pathways combine to form a complex regulatory network for spermatogenesis. In testicular tumors or infertile patients, the activities of these signaling pathways in Sertoli cells are abnormal. Clarifying the mechanisms of signaling pathways in Sertoli cells on spermatogenesis provides new insights into the physiological functions of Sertoli cells in male reproduction, and also serves as a pre-requisite to identify potential therapeutic targets in abnormal spermatogenesis including testicular tumor and male infertility.
\end{abstract}

Facts

- Sertoli cells support, nourish, and protect spermatogenic cells via various signal pathways.

- The TGF- $\beta /$ Smad, AMPK, and MAPK signaling pathways in Sertoli cells support spermatogenesis via regulating cell junction dynamics, proliferation of Sertoli cells and germ cells, and lactate supply for spermatids.

- Activity of the TGF- $\beta /$ Smad, AMPK, and MAPK signaling pathways in Sertoli cells turns abnormal in non-obstructive azoospermia and patients with testicular cancer.
Correspondence: Wan-Xi Yang (wxyang@spermlab.org)

'The Sperm Laboratory, College of Life Sciences, Zhejiang University, 310058 Hangzhou, Zhejiang, China

These authors contributed equally: Fei-Da Ni, Shuang-Li Hao Edited by A. Stephanou

\section{Open questions}

- Which pathway plays a decisive role when the TGF$\beta /$ Smad, AMPK, and MAPK signaling pathways in Sertoli cells regulate the same process?

- What are the detailed molecular downstream mechanisms and interactions of proteins involved in the pathways mediating physiological functions of Sertoli cells?

- What is the key role of the TGF- $\beta /$ Smad, AMPK, and MAPK signaling pathways in tumorigenesis and infertility?

- Is it possible to identify specific pathways and related proteins as diagnostic and therapeutic targets for testicular cancer and male infertility?

\section{Introduction}

Spermatogenesis is a significant physiological process of sperm production in the epithelium of the seminiferous tubules ${ }^{1}$. In this process, spermatogonial stem cells (SSCs) 
are triggered to produce spermatogonia, which will transform to spermatocytes, spermatids, and finally mature spermatozoa ${ }^{2,3}$. The migration of germ cells (GCs) and the release of spermatozoa require timely cell junctions disassemble and reassemble between Sertoli cellsSertoli cells (SCs-SCs) and SCs-GCs ${ }^{4,5}$. Such adherens junctions (AJs) are named as ectoplasmic specializations (ES) in the testis, and are divided into the basal ES at the SCs-SCs interface and the apical ES at the SCs-spermatids interface $^{6}$. In the mammalian testis, the basal ES, desmosomes, gap junctions, and tight junctions (TJs) between $\mathrm{SCs}$ form the blood-testis barrier $(\mathrm{BTB})^{7}$. The TJs at the BTB are constituted of various tight junctional proteins, including the claudin (CLDN) family, junctional adhesion molecule (JAM) family, etc. (for reviews, see ref. $\left.^{8}\right)$, which will bind to actin via the zonula occludens- 1 , -2 and -3 (ZO-1, ZO-2 and ZO-3) in SCs ${ }^{9}$. At stage VIIVIII of the epithelial cycle, the preleptotene and leptotene spermatocytes must move through the BTB and enter the adluminal compartment ${ }^{10}$. Most researchers focused on the synchronization of spermatogenesis currently, but few of them have addressed the issue from the perspective of Sertoli cells ${ }^{11-17}$.

Sertoli cells are the only somatic cells in the seminiferous epithelium ${ }^{18}$. Throughout mammalian spermatogenesis, SCs provide morphogenetic support via cell-cell interactions and also biochemical components via secreting lactate, cytokines, and hormones ${ }^{19,20}$. Apart from the mechanical and nutritional support, SCs also form an immune-protective environment to protect germ cells via the $\mathrm{BTB}^{21-24}$. At the end of spermatogenesis, $\mathrm{AJs}$ between GCs and SCs allow SCs endocytosis of the elongated spermatids' cytoplasm, and finally morphologically shape the spermatids ${ }^{25}$. Therefore, SCs are considered as nurse like cells to support spermatogenesis ${ }^{26}$.

Accumulating studies have indicated that various signaling pathways in SCs are implicated with spermatogenesis $^{27,28}$. Until now, numerous signaling pathways have been found in Sertoli cells, including the androgensignaling pathway ${ }^{29,30}$, the AMP-activated protein kinase (AMPK) signaling pathway ${ }^{31}$, the follicle stimulating hormone (FSH)/adenylate cyclase/cyclic adenosine monophosphate (cAMP)/protein kinase A (PKA) signaling pathway ${ }^{32}$, the Hippo signaling pathway ${ }^{33,34}$, the intergrin mediated signaling pathway ${ }^{4,35}$, the Janus kinase/signal transducer and activator of transcription signaling pathway ${ }^{36,37}$, the mitogen-activated protein kinases (MAPK) signaling pathway ${ }^{38-44}$, the nuclear factor kappa B signaling pathway ${ }^{45,46}$, the nitric oxide/soluble guanylyl cyclase/cyclic guanosine monophosphate/ protein kinase G signaling pathway ${ }^{47,48}$, the Notch signaling pathway ${ }^{49}$, the phosphatidylinositol-4,5-bisphosphate 3-kinase (PI3k)/AKT serine/threonine kinase (Akt) signaling pathway ${ }^{50,51}$, the Sonic Hedgehog signaling pathway ${ }^{52,53}$, the transforming growth factor- $\beta$ (TGF- $\beta$ )/ Smad signaling pathway ${ }^{54}$, and the Wnt signaling pathway $^{55,56}$ (Table 1). Among all these signaling pathways, the TGF- $\beta /$ Smad, AMPK, and MAPK signaling pathways have attracted much more attentions in the past decade. In this review, we aim to summarize the impact mechanisms of these three pathways in SCs on spermatogenesis (Fig. 1). These three signaling pathways play dominant functions in SCs, which support the spermatogenesis via jointly affecting SCs proliferation, $\mathrm{AJ}$ and $\mathrm{TJ}$ dynamics. Moreover, the MAPK and AMPK signaling pathway affect lactate supply in SCs, while the MAPK signaling pathway also occupies a dominant position in regulating SSCs self-renewal.

\section{The TGF- $\beta$ /Smad signaling pathway}

The transforming growth factor- $\beta$ (TGF- $\beta$ ) superfamily contains activin, inhibin, bone morphogenetic proteins (BMPs), growth and differentiation factors (GDFs), and TGF- $\beta$ homodimeric proteins ${ }^{57-59}$. Smad4 serves as a crucial mediator of upstream signals in the TGF- $\beta / \mathrm{Smad}$ signaling pathway upon TGF- $\beta$ s stimulation. Although Smad1, 3, 5, 6, 7, 8 express discriminately at birth, stages $\mathrm{V}$, VII, VIII, XV, and adult based on immunohistochemical detection and RT-PCR results, Smad4 are distributed within SCs at all ages in mice and domestic fowl ${ }^{60-63}$. When Smad4 was conditionally deleted in mouse Sertoli cells, the fertility of mutant mouse was impaired with smaller testis size and decreased sperm production at adult $^{64}$. The various trends of Smad expression and deleted phenotype demonstrate that the TGF- $\beta / S$ mad signaling pathway occupies a continuous crucial position for SCs function during spermatogenesis, while different members of the TGF- $\beta$ superfamily may perform their functions at different stages (Fig. 2).

\section{SCs proliferation}

Precisely regulated $\mathrm{Smad} 2 / 3$ signaling is required for $\mathrm{SCs}$ to differentiate from the proliferating state to a differentiated state. Type IIA activin receptor exhibits high-expression transiently in rat SCs at stage VII$\mathrm{IX}^{65,66}$. Consistent with this, Itman et al. found that activin-induced nuclear accumulation of Smad2 and Smad3 in post mitotic mouse SCs, and also screened out the activin target genes Gja1 and Serpina5 via microarray analysis. These two genes encode connexin 43 and serine protease inhibitor, respectively, which are required for SCs maturation ${ }^{54}$. In $\mathrm{Smad}^{-1-}$ mouse, delayed SCs differentiation and decreased testis size were accompanied by an inhibition of androgen receptor and Smad2 expression ${ }^{67}$. Uncovering the link between Smad2/3 and their downstream network may make us benefit in studying the effects of SCs proliferation on sperm output. 


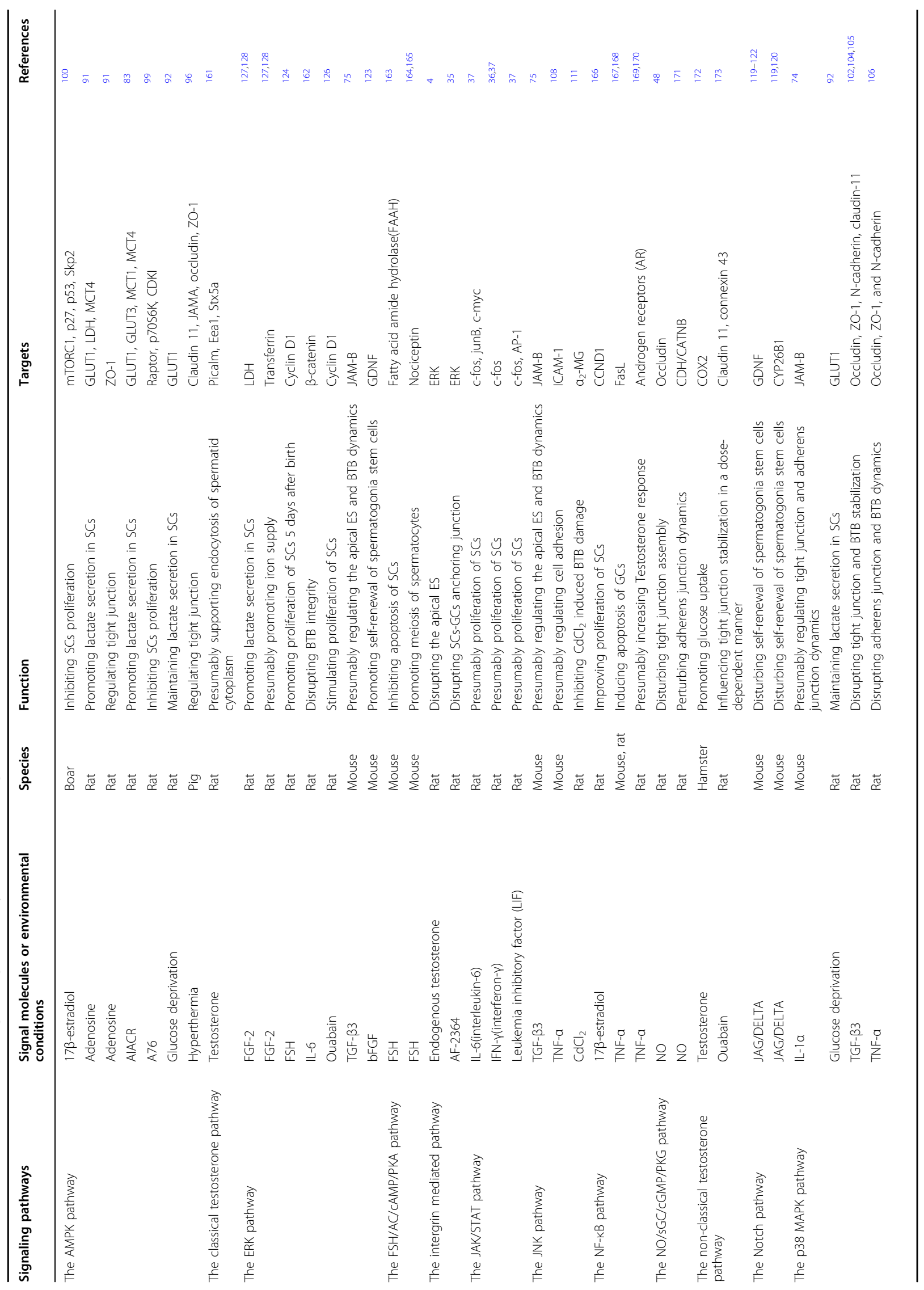




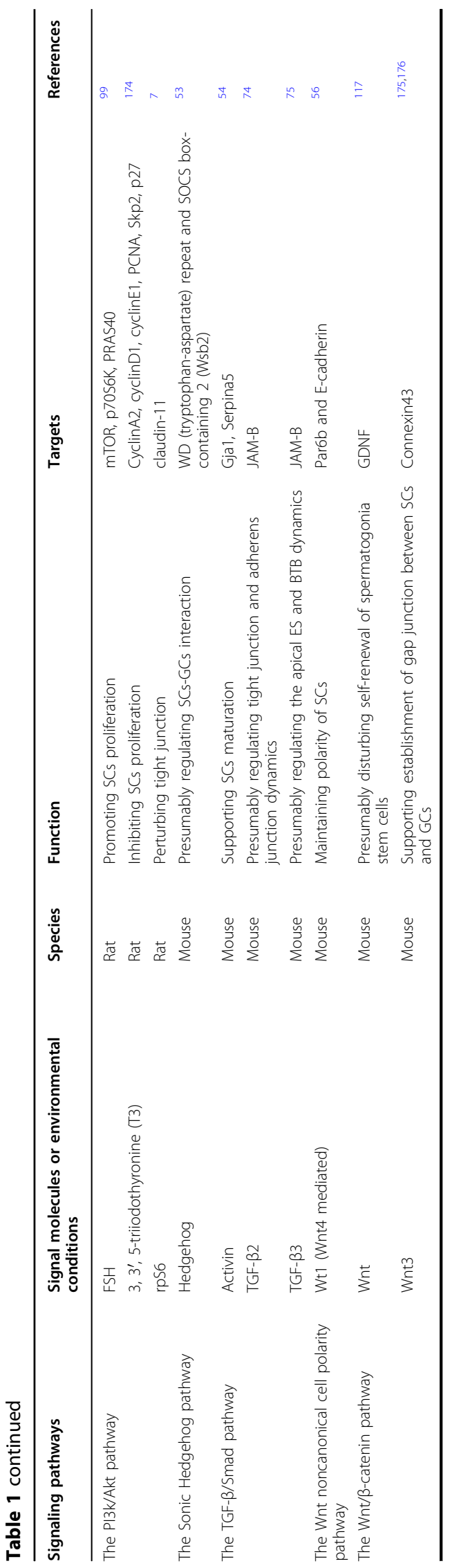

BMP4 and BMP6 promote proliferation and DNA synthesis of human SCs via an autocrine pathway ${ }^{68,69}$. BMP4 was observed to increase Smad1/5 phosphorylation and to enhance proliferation of human SCs, but administration of noggin, the BMP4 antagonist, showed conversely inhibitory effects. When Hai et al. knocked down BMP4 in human SCs, fibroblast growth factor-2 (FGF-2) and SCF production was also suppressed ${ }^{70}$. However, the contribution of Smad1/5 pathway against the ID2/3 pathway in BMP4-induced SCs proliferation enhancement was not evaluated in their research. This problem also exists in the study of BMP6, particularly, whether the Smad2/3 signaling pathway directly mediates the BMP6-induced proliferation, and increased levels of SCF and Glial cellderived neurotrophic factor (GDNF) in human $\mathrm{SCs}^{71}$.

\section{TJs and AJs dynamics}

TGF- $\beta s$ and GDF9 participate in the regulation of TJs and AJs dynamics. Given that the transition and relocation of spermatocytes through the BTB require coordinated disassembly and reassembly of cell junctions, timely regulation of JAM-B expression is crucial for migration of $\mathrm{GCs}^{72,73}$. Both TGF- $\beta 2$ and TGF- $\beta 3$ downregulate the expression of JAM-B via the Smad3 signaling pathway. Wang and Lui discovered that in mouse SCs, TGF$\beta 2$ served as an anti-expression factor of JAM-B at the pretranscriptional level. TGF- $\beta 2$ increases phosphorylation level of Smad3, which would compete with the transcription factors Sp1 and Sp3 for the TG interacting factor (TGIF) motif, and ultimately repress the JAM-B transcription $^{74}$. However, TGF- $\beta 3$ treatment can decrease the JAM-B protein level at a post-translational way in mouse SCs. The degradation of JAM-B can be relieved upon administration of proteasome inhibitors, including MG132 and lactacystin. This process requires Smad3/4 activation. If Smad3 and Smad4 are knocked down, TGF- $\beta 3$ induced JAM-B degradation will be inhibited in $\operatorname{turn}^{75}$. Consequently, TGF- $\beta 2$ and TGF- $\beta 3$ may establish a precise-regulating network for disassembly and assembly of the BTB via the Smad signaling pathway.

Apart from JAM-B, Smad3 also supports preleptotene spermatocytes translocation by decreasing CLDN11 expression in mouse TM4 cell lines ${ }^{76}$. As a component of T), CLDN11 is crucial for spermatocyte migration through the BTB into the adluminal compartment ${ }^{77-79}$. When the Smad signaling pathway is stimulated in TM4 cells, Smad3/4 binds to the GATA/NF-Y motif in CLDN11 promoter. Quantity of the complex formed in this way will be decreased upon anti-Smad3 antibody treatment in the electrophoretic mobility shift assay. Ulteriorly, the binding complex can recruit histone deacetylase 1 and co-repressor mSin3A. Thus, transactivation of GATA and CREB, as well as the activity of the promoter in CLDN11 gene were inhibited ${ }^{76}$. 


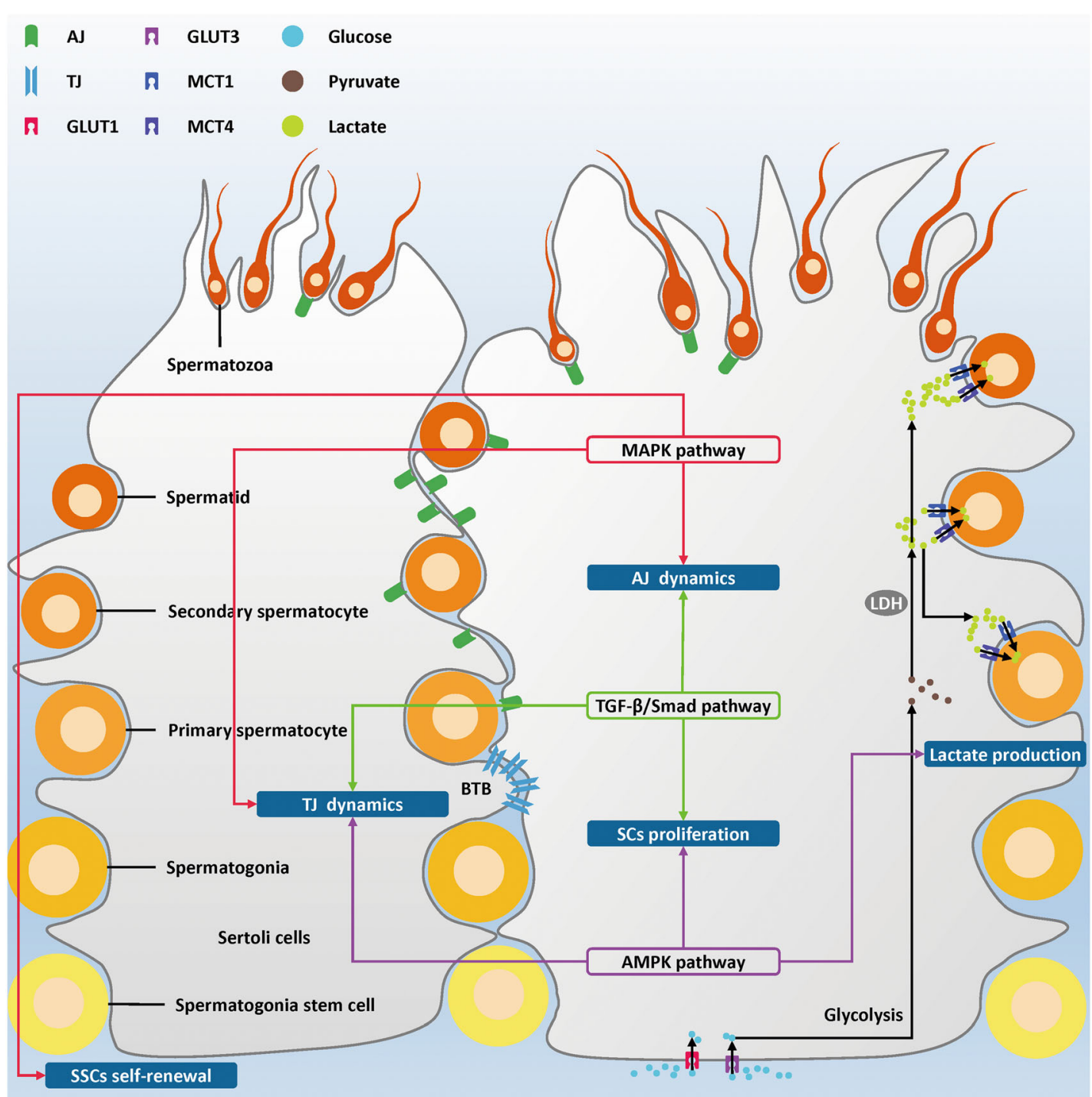

Fig. 1 Schematic diagram illustrating the integrated influence of the TGF- $\beta / S$ mad, AMPK, and MAPK signaling pathways in SCs on spermatogenesis. The TGF- $\beta / S$ mad signaling pathway regulates spermatogenesis via controlling AJ, TJ dynamics, and Sertoli cell proliferation (green). The AMPK signaling pathway regulates TJ dynamics, lactate production, and Sertoli cell proliferation (purple). The MAPK signaling pathway influences AJ, TJ dynamics, and spermatogonia stem cell self-renewal, and ultimately supports spermatogenesis (red)

Few researches have addressed the issue on the GDF9/ Smad signaling pathway, but Nicholls et al. did detect disruption of the inter-Sertoli TJ permeability barrier after adding recombinant GDF9 in mouse SCs cultures ${ }^{80}$. GDF9 receptor ALK5 and Smad2/3 were highly detected in adult alpaca and cat $\mathrm{SCs}^{81,82}$. Here, we suggest that further experimental investigations should focus on whether GDF9 regulates TJs via the GDF9/Smad2/3 signaling pathway.

\section{The AMPK signaling pathway}

The AMPK is a kind of heterotrimeric Ser/Thr kinase, which serves as the sensitive energy sensor and cellular energy metabolism regulator in Sertoli cells ${ }^{19,83}$. The AMPK signaling pathway in SCs has been found to regulate energy metabolism, junctional complex stability, and proliferation $^{84}$. Once the balance is disrupted, the microenvironment of testis and the quality of sperm will be affected. For example, in $\alpha 1$ AMPK globally knocked out mouse, spermatozoa showed abnormal head, curved sheaths, and impaired mobility ${ }^{85}$. When $\alpha 1 \mathrm{AMPK}$ is conditionally knocked out in mouse SCs, the mutant mice still showed an abnormal phenotype, including thin head spermatozoa, reduced expression of junctional proteins ( $\beta$-catenin, vimentin, occludin and ZO-1), and deregulation of energy homeostasis ${ }^{86}$. These findings support the 


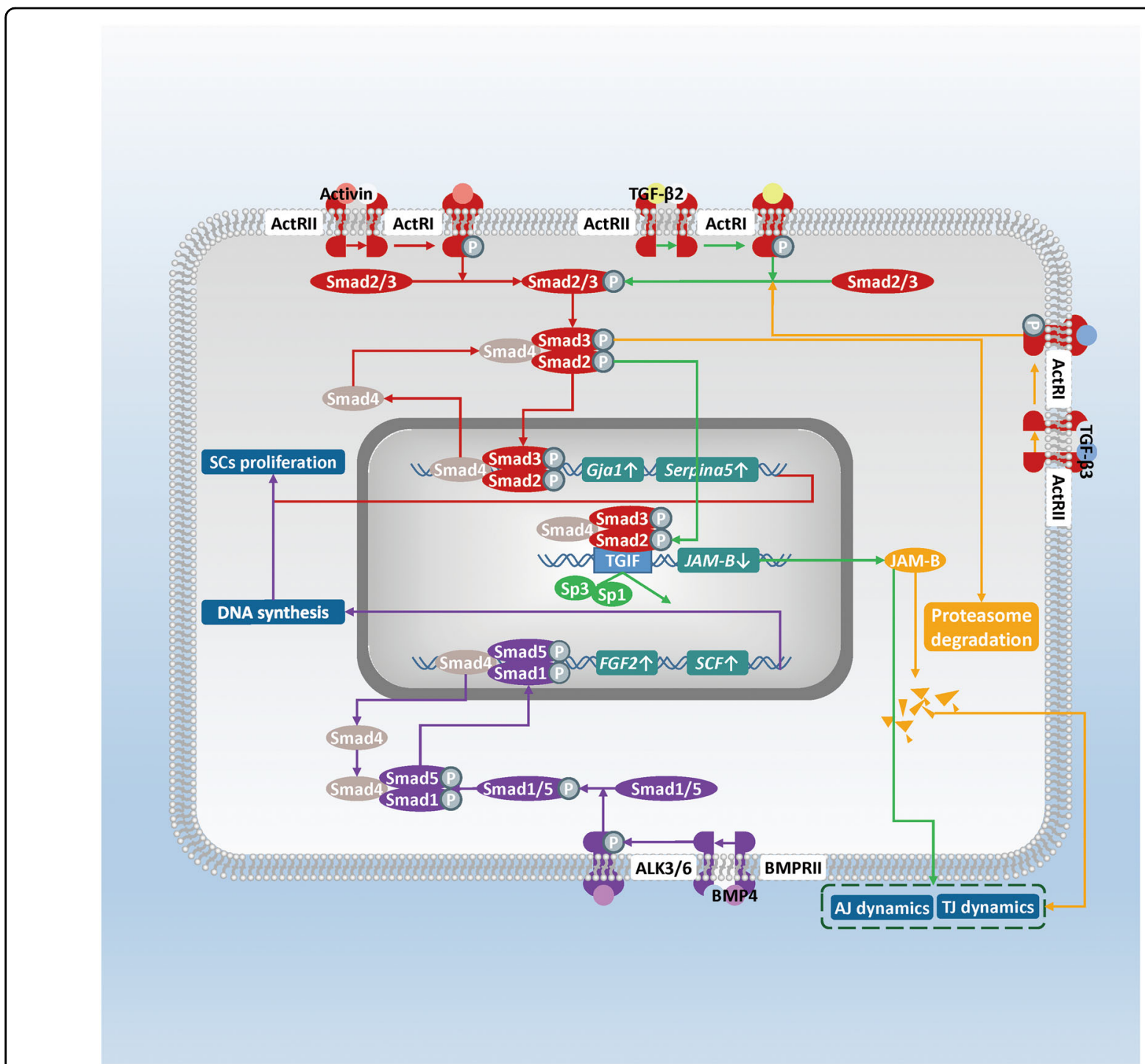

Fig. 2 Schematic diagram illustrating the influence of the TGF- $\beta / S m a d$ signaling pathway in SCs on spermatogenesis. Members of TGF- $\beta$ family activate the pathway via binding to TGF $\beta R I I$ and recruiting TGF $\beta R I$. Different TGF- $\beta$ s bind to their corresponding receptor complexes, but all activated TGF $\beta R I$ can phosphorylate members of Smad family, which are divided into 3 subfamilies including the receptor-regulated Smads (RSmads, Smad1, 2, 3, 5, 8), the common Smad (Co-Smad, Smad4), and the inhibitory Smads (I-Smads, Smad6, 7). After TGF $\beta R$ I phosphorylates R-Smad, R-Smad will detach from TGF $\beta R$ I and bind to Smad4. Then the heteromeric complex translocates into the nucleus, binds to the promoter region and alters transcription of target gene with co-factors. (Red) Activin binds to type IIA activin receptor to activate the activin/Smad2/Smad3 pathway, then expression levels of Gja1 and Serpina5 rise to affect SCs maturation. BMP4 activates the BMP4/Smad1/Smad5 pathway via binding with BMPRII, and then promotes DNA synthesis and SCs proliferation (purple). Both TGF- $\beta 2$ and TGF- $\beta 3$ will inhibit the JAM-B expression level. TGF- $\beta 3$ lowers the JAMB protein level via activating TGF- $\beta 3 / \mathrm{Smad} 2 / \mathrm{Smad} 3$ pathways to induce the ubiquitin-proteasome degradation (orange). TGF- $\beta 2$ activates Smad3 (green). Then Smad3 can compete with Sp1 and Sp3 and inhibit the JAM-B transcription

contribution of the AMPK signaling pathway in SCs during spermatogenesis (Fig. 3).

\section{Lactate production}

Lactate is a preferring energy source of spermatocytes and spermatids, the majority of which is provided by Sertoli cells ${ }^{87,88}$. SCs will actively convert glucose mainly into lactate. In this process, glucose transporters (GLUTs) regulate glucose metabolism via limiting substrate transmembrane transport, while monocarboxylate transporters (MCTs) control lactate transport and supply to GCs, both of which contribute to adjust lactate production in $\mathrm{SCs}^{83,89,90}$.

In response to various signaling factors and environmental conditions, the AMPK signaling pathway in SCs serves as a key regulator in providing lactate for energy 


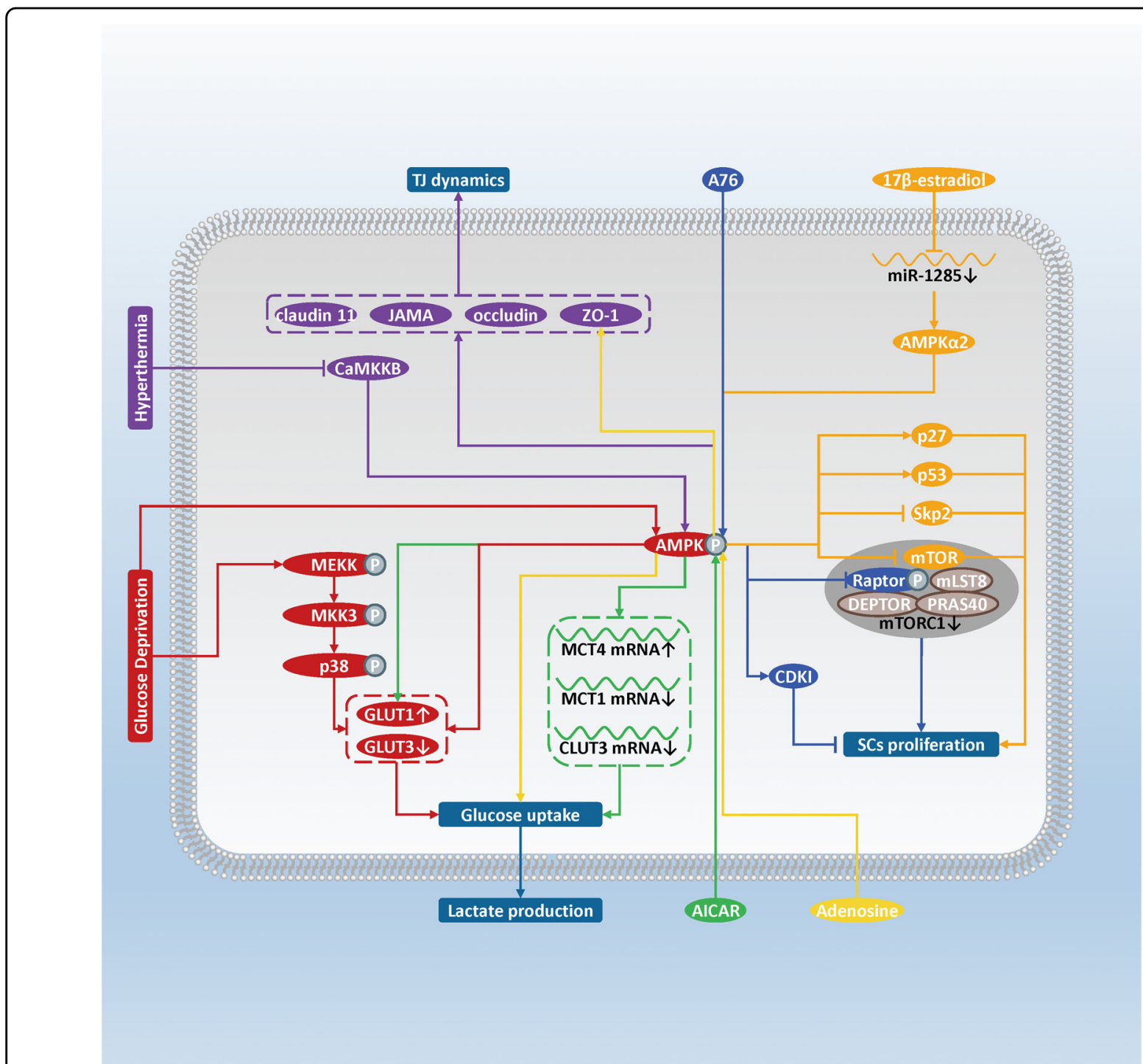

Fig. 3 Schematic diagram illustrating the influence of the AMPK signaling pathway in SCs on spermatogenesis. AMPK is sensitively stimulated by the rise of intracellular AMP: ATP ratio, while phosphorylation induced by upstream AMPK kinases (i.e., liver kinase B1 [LKB1] and (aMKKB) and AMP binding will also stimulate AMPK. Glucose deprivation activates the AMPK and p38 MAPK pathways to upregulate GLUT1 but downregulate GLUT3 (red). Activation of the AMPK signaling pathway induced by adenosine analog AICAR increases GLUT1 expression and MCT4 mRNA, but decreases MCT1 and GLUT3 mRNA, thus promoting glucose uptake and lactate secretion (green). Adenosine also promotes lactate secretion and stabilizes ZO-1 on SCs membrane via activating the AMPK pathway (yellow). Hyperthermia inhibits CaMKKB to block the AMPK pathway, and, therefore, affects TJ protein expression (purple). AMPK activates CDKI but phosphorylates Raptor to inhibit mTORC1, thus blocking the SCs proliferation (blue). 17ß-estradiol inhibits miR-1285 expression to maintain a2AMPK level (orange). This way, activation of AMPK is retained, which upregulates $p 53$ and p27 expression but downregulates mTOR and Skp2 expression, resulting finally in the reduction of the SCs number

metabolism of GCs and maintaining spermatogenesis ${ }^{91}$. Glucose deprivation in rat SCs will induce activation of the AMPK and p38 MAPK signaling pathway, increase the mRNA level of GLUT1 and maintain the uptake of glucose. Such adaptation ensures or rescues lactate production even in the absence of glucose ${ }^{92-94}$. Adenosine and its analog AICAR were also proven to promote lactate secretion from rat SCs via AMPK activation, while mechanism of AIACR regulation is illustrated more integrally ${ }^{83,91}$. AICAR can increase lactate production via the AMPK-induced glucose intake in rat SCs, at least through increase in GLUT1 protein level and MCT4 mRNA level, and decrease in MCT1 and GLUT3 mRNA levels ${ }^{83,95}$. Overall, adaptation to the environment and response to those signal molecules via the AMPK signaling pathway in SCs will thus stabilize an appropriate lactate supply for GCs energy demand. 


\section{TJs and AJs dynamics}

The AMPK signaling pathway maintains junctional complex stabilization in testis. It has been shown that activation of AMPK by adenosine stabilizes $\mathrm{ZO}-1$ on rat SCs membranes, and the AMPK inhibitor compound $\mathrm{C}$ can decline adenosine affected ZO- $1^{91}$. Also, heat stress can cause dysfunction of TJs in porcine testis reversibly via $\mathrm{Ca}^{2+} /$ calmodulin-dependent protein kinase kinase $\mathrm{B}$ (CaMKKB) induced inhibition of the AMPK signaling pathway. Yang et al. treated SCs from 3-week-old piglets at $43{ }^{\circ} \mathrm{C}$ for $0.5 \mathrm{~h}$, and such hyperthermia inhibited the AMPK signaling pathway to inhibit expression of CLDN11, JAMA, occludin, especially ZO-1 in porcine $\mathrm{SCs}^{96}$

As for AJs, the relationship has been clarified between the $26 \mathrm{~S}$ proteasome inhibitor bortezomib, the AMPK signaling pathway and AJs among SCs and GCs in mouse. Bortezomib can induce AMPK activation and then antagonize Akt and extracellular signal-regulated kinase (ERK) signaling pathway in mouse SCs. As a consequence, AJs impairment, immature GCs desquamation and sperm quantity reduction are followed ${ }^{97}$. Based on this phenomenon observed in bortezomib exposure, we suggest that the detailed mechanisms of the normal situation are also worth studying.

\section{SCs proliferation}

Apart from regulating AJs integrity, SCs proliferation inhibition is also mediated by the AMPK signaling pathway $^{98}$. AMPK activation potentially leads to detention of rat SCs proliferation at least partially by inhibition of mTORC1 and stimulation of cyclin-dependent kinase inhibitors expression. Moreover, lower activity of mTORC1 was due to accumulation of phosphorylated Raptor $^{99}$. Consequently, SCs mitotic activity, which is stimulated by FSH and mediated by the PI3K/Akt signaling pathway, is counteracted by the AMPK signaling pathway. Similarly, the activated AMPK signaling pathway also mediated $17 \beta$-estradiol inhibition on boar SCs proliferation, which would be abolished by compound $\mathrm{C}$ treatment. Zhang et al. administrated $10 \mu \mathrm{M}$ of $17 \beta$-estradiol on boar SCs and observed inhibition of miR-1285 expression ${ }^{59}$. Recently, they clarified that miR1285 can downregulate $\alpha 2$ AMPK mRNA and protein level. $17 \beta$-estradiol treatment retains AMPK activity by maintaining $\alpha 2 \mathrm{AMPK}^{31}$. As for the downstream effect, the phosphorylated AMPK increases the expression of the cyclin-dependent kinase inhibitor p27 (p27) and tumor suppressor p53 (p53), but inhibits the protein level of phosphorylated mTOR and S-phase kinase-associated protein $2(\mathrm{Skp} 2)^{100}$. This regulatory network ultimately leads to reduction of SCs number and sperm production in boars.

\section{The MAPK signaling pathway}

MAPKs belong to the Ser/Thr kinase family. There are three major subfamilies of MAPKs, i.e., c-Jun $\mathrm{N}$-terminal kinase (JNK), ERK, and p38 MAPK (MAPK14). The isoforms and distribution of JNKs, ERKs and p38 MAPKs present in mammalian SCs have been summarized. In rat testis, (phosphorylated) ERK1/22, (phosphorylated) JNK1/ 2, (phosphorylated) p38 MAPK are located in SCs, while ERK7, JNK3 are investigated in testis (for reviews, see ref. ${ }^{1}$ ). According to the microarray data, a majority of MAPK pathway-related genes exist in immature rat SCs, which shows the existence of the MAPK signaling cascades in $\mathrm{SCs}^{101}$ (Fig. 4).

\section{The 38 MAPK signaling pathway: TJs and AJs dynamics}

The p38 MAPK signaling pathway participates in the multiple signaling pathway network involved in regulating JAM-B. We have described above how TGF- $\beta 2$ and TGF$\beta 3$ suppress expression of JAM-B via the TGF- $\beta /$ Smad signaling pathway. Herein, the p38 MAPK signaling pathway also involves in the interleukin-1 $\alpha$ (IL- $1 \alpha)$ promotion of JAM-B transcription in rat SCs. Activated p38 MAPK phosphorylated the ETS domain transcription factor (Elk-1). Phosphorylation allows Elk-1 to bind on TGIF and proximal Sp1 (pSp1) +E2F motifs. Such interaction will increase $\mathrm{Sp} 1$ and NRSF trans-activated $J A M-B$ transcription finally ${ }^{74}$. We would like to mention the two other MAPK subfamilies, JNK and ERK here, for their effects on destabilization of JAM-B mRNA transcript via post-transcriptional regulation upon TGF$\beta 3$ stimulation in mouse $\mathrm{SCs}^{75}$.

Moreover, TGF- $\beta 3$ has been found to perturb TJs barrier assembly in the $\mathrm{p} 38$ MAPK signaling pathway via a transient increase in phosphorylated p38-MAPK instead of overall p38 MAPK ${ }^{102,103}$. Overexpression of TGF- $\beta 3$ in primary rat SCs can magnify above damage effect in vitro, with occludin, $\mathrm{N}$-cadherin, and $\mathrm{ZO}-1$ decline $\mathrm{e}^{104}$. In $\mathrm{CdCl}_{2}$-induced adult rat BTB damage, a specific p38 MAPK activity inhibitor SB202190 can blocked loss of ZO-1 and occludin, and thus abolish the damage of TGB$\beta 3$ on the $\mathrm{AJ}$ and $\mathrm{TJ}$ barrier function. It strengthens the physiological importance of the TGF- $\beta 3 / \mathrm{p} 38$ MAPK signaling pathway in $\mathrm{AJ}$ and $\mathrm{TJ}$ dynamics ${ }^{105}$.

The event differs when the p38 MAPK signaling pathway and/or the ERK signaling pathway regulate cell junctions upon TGF- $\beta 3$ and tumor necrosis factor $\alpha$ (TNF- $\alpha$ ) treatment. After adapter CD2-associated protein (CD2AP) binds to TGF- $\beta 3$ and TGF- $\beta$ receptor I (TGF $\beta R I$ ) complex, the BTB integrity remains normal, but SCs-GCs adhesion is disrupted reversibly via the activated ERK-signaling pathway in rat SCs. However, when both TAK1-binding protein 1 (TAB1) and CD2AP bind to TGF $R$ I, the p38 MAPK and ERK signaling pathway are 


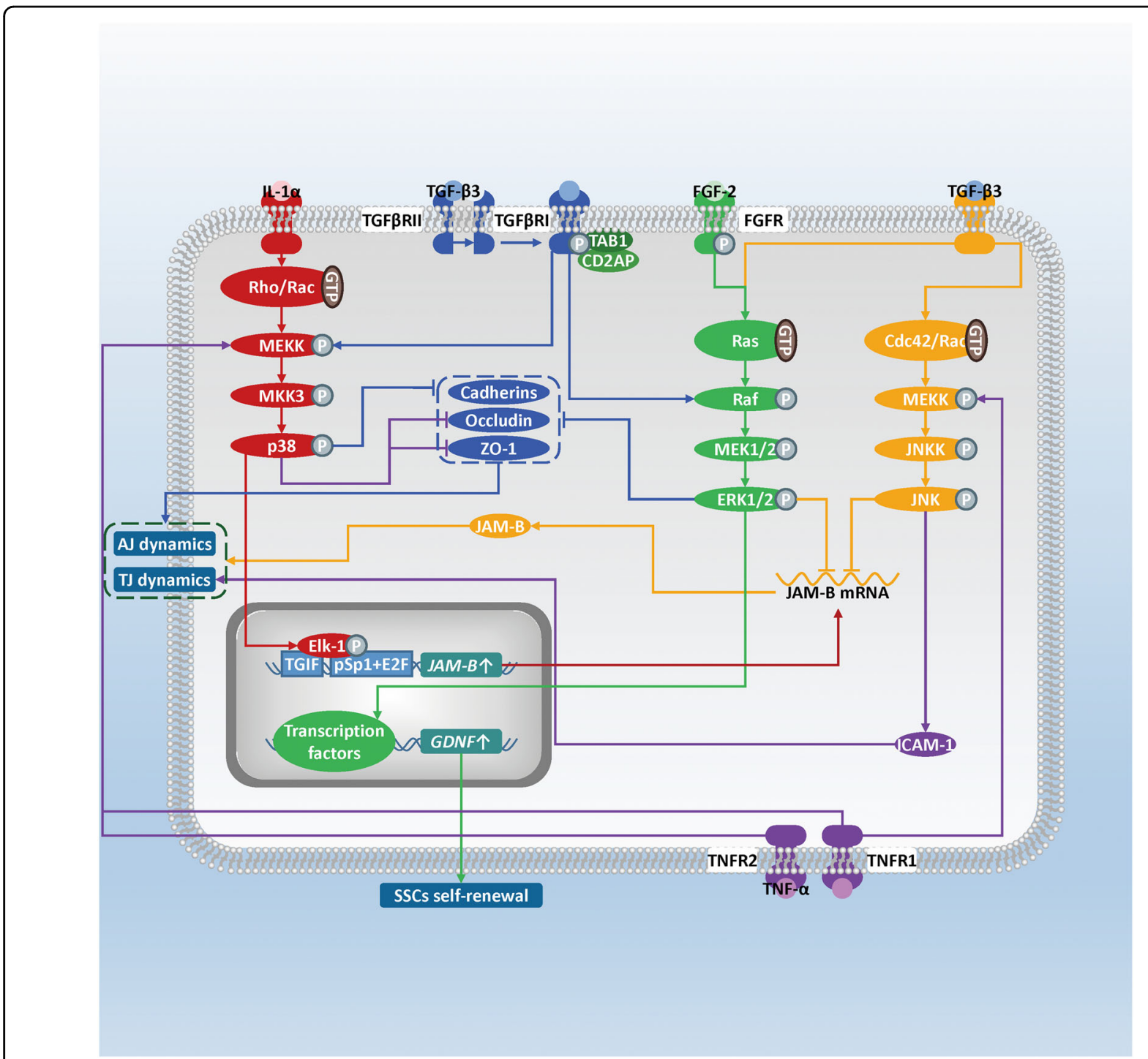

Fig. 4 Schematic diagram illustrating the influence of the MAPK signaling pathway in SCs on spermatogenesis. MAPKs Consist of JNKs, ERKs, and p38 MAPKs. After MAPKKK is activated by the signal, MAPKK and then MAPK are activated via phosphorylation. The activated MAPK will then phosphorylate its substrates. IL-1a activates via the p38 MAPK pathway, then the phosphorylated p38 MAPK phosphorylates Elk-1 and allows Elk-1 to bind onto TGIF and pSp1 + E2F motifs, which thus stimulates JAM- $B$ transcription (red). Activation of the ERK and JNK pathways induced by TGF- $\beta 3$ will promote JAM-B mRNA destabilization (orange). When TAB1 and CD2AP both interact with TGF- $\beta 3$-TGF $\beta R I$, the activated p38 MAPK and ERK pathways will downregulate expression of occludin, ZO-1 and cadherin, and disturb SCs-GCs AJs and BTB (blue). TNF- $a$ administration will decrease occludin and ZO-1 via the p38 MAPK pathway but also increase ICAM-1 via the JNK pathway, thus regulating the AJ and TJ dynamics (purple). FGF-2 activates the ERK pathway to stimulate GDNF expression, thus enhancing SSCs self-renewal (green)

both activated. Not only occludin, ZO-1 at the BTB, but also cadherins at the apical ES and BTB decreases, which leads to disruption of SCs-GCs adhesion and the BTB as well ${ }^{104}$. As for TNF- $\alpha$, it binds to TNFR1 and/or TNFR2 on rat SCs membrane and activates only p38 MAPK without ERK, downregulating occludin and ZO-1 expression transiently to allow relocation of preleptotene and leptotene spermatocytes crossing the BTB and differentiation of them to pachytene spermatocytes $^{106}$.

\section{The JNK signaling pathway: TJs and AJs dynamics}

Recent evidences strongly support that the JNK signaling pathway contributes to the BTB function and GCs migration. Intercellular adhesion molecule-1 (ICAM-1) is the constitution of BTB and a pivotal regulator in $\mathrm{BTB}$ dynamics, which is co-localized with occludin and Ncadherin ${ }^{6}$. After transfected with pCI-neo/ICAM-1 plasmids, the rat SCs overexpressed ICAM-1 with increase of transepithelial electrical resistance and enhancement of TJs barrier function ${ }^{107}$. TNF- $\alpha$ stimulation on JNK is 
related to ICAM-1. After secreting from round spermatids, TNF- $\alpha$ binds to the p55 receptors (TNFR1) on mouse SCs membrane, activates the JNK signaling pathway and thus increases ICAM-1 expression ${ }^{108,109}$. Further studies need to focus on whether ICAM-1 overexpression can stabilize TJ dynamics in vivo upon TNF- $\alpha$-activated JNK pathway.

Furthermore, the JNK signaling pathway will also reduce $\mathrm{CdCl}_{2}$-induced $\mathrm{BTB}$ disruptive effects in adult rats, which is just contrary to the p38 MAPK signaling pathway. During $\mathrm{CdCl}_{2}$-induced BTB disruption, the JNK signaling pathway leads to $\alpha_{2}$-macroglobulin $\left(\alpha_{2}-\mathrm{MG}\right)$ expression, which is a protease inhibitor localized at the SCs-SCs and SCs-GCs interface ${ }^{110}$. Wong et al. used the protein kinase inhibitor 6-dimethylaminopurine which can downregulate $\alpha_{2}$-MG protein level to examine its effect ${ }^{111}$. After 6-dimethylaminopurine pretreatment before $\mathrm{CdCl}_{2}$ administration in rat, they observed losing of GCs and flaking of the most seminiferous epithelium in the basement membrane ${ }^{111}$. These evidences reveal the importance of $\alpha_{2}$-MG in inhibiting unwanted proteolysis and maintaining TJs and AJs integrity in defending the $\mathrm{CdCl}_{2}$-induced BTB disruption.

\section{The ERK signaling pathway \\ $G C s$ proliferation and meiosis}

Different from the JNK and p38 MAPK signaling pathways, the ERK signaling pathway directly regulates apoptosis, mitosis, and meiosis progression of GCs. In situ hybridization of mouse testis and primary cell culture have confirmed that fibroblast growth factor-4 (FGF-4) expresses only in Sertoli cells throughout the spermatogenic cycle ${ }^{112}$. Hirai et al. investigated that overexpression of FGF-4 in mouse SCs inhibited apoptosis of GCs due to mild hyperthermia. They injected mice with recombinant FGF-4 adenovirus and then treat them at $43^{\circ} \mathrm{C}$ for 15 min after 5 days. Dissection of testis showed fewer sperm count and less testicular weight in response to mild heat treatment than that of control, along with the increase of phosphorylation level of the ERK1/2 in mouse SCs and GCs. It indicates the potential mechanism that FGF-4 prevents GCs from apoptosis and promotes GCs survival via triggering the ERK signaling pathway in SCs and GCs ${ }^{113,114}$.

Furthermore, meiosis of spermatocytes depends on activation of the ERK signaling pathway in co-culture of SCs and pachytene spermatocytes. Godet et al. detected the phosphorylated ERK1/2 in such co-culture. After pretreatment of MEK1/2 inhibitor U0126, the number of pachytene spermatocytes and secondary spermatocytes declined. But no similar phenomenon emerged in pachytene spermatocytes culture upon U0126 treatment. These different phenomena emphasize the determination of the ERK signaling pathway in SCs for spermatocytes meiosis $^{115}$.
GDNF has been identified as a paracrine factor to promote proliferation and migration, but prevents differentiation of SSCs via binding onto the RET/GFR $\alpha 1$ coreceptors and activating of Ras/ERK1/2 signaling pathway in $\mathrm{SSCs}^{16,28,116}$. GDNF expression in mouse SCs can be upregulated via the cAMP/PKA signaling pathway and the Wnt/ $\beta$-catenin signaling pathway ${ }^{117,118}$, but be downregulated by the Notch signaling pathway ${ }^{119-122}$. Mouse SCs also use the ERK signaling pathway for regulating GNDF expression and thus influencing SSCs niches. During the self-renewal phase of mouse SSCs, the level of GDNF in SCs rises with the activation trend of ERK 1/2 in $\mathrm{SCs}$, which preserves the undifferentiated state of $\mathrm{SSCs}^{123}$.

\section{SCs proliferation}

FSH decides the states of the ERK signaling pathway at a stage-dependent manner in SCs, with each stage activated or inhibited. At 5 days after birth, FSH treatment on isolated rat SCs stimulated MEK-1 activation, and then increased phosphorylation and nucleic relocation level of ERK1/2, the former of which can be eliminated by preincubation of SCs with MEK-1 inhibitor PD98059. This way, the expression of cyclin D1 (CCND1) and proliferation rate of the neonatal SCs are promoted. However, SCs maturation stage displays an opposite effect of FSH on the ERK signaling pathway. At 19 days after birth, FSH treatment turns to inhibit the ERK signaling pathway in rat SCs, leaving number of S-phase SCs and protein level of CCND1 less sensitive to FSH stimulation ${ }^{124}$. Similar trends of phosphorylated ERK were also detected in normal mice, though without FSH treatment in vitro, where phosphorylation level of ERK increased until puberty, followed by a decrease during adulthood in wild type mice $^{125}$.

Furthermore, ouabain, which is a mammal adrenal gland cortex-produced endogenous cardiotonic steroid, can induce CCND1 expression and primary rat SCs proliferation accompanied with activation of the ERK signaling pathway ${ }^{126}$. We have addressed the changes in phosphorylated ERK levels is consistent with the proliferation of SCs, so that the periodical rising and falling of the ERK signaling pathway activation are probably closely linked with numbers of SCs and differentiated GCs during testicular development.

\section{Lactate and iron supply}

FGF-2 utilizes the ERK signaling pathway to regulate transferrin secretion and lactate dehydrogenase (LDH) activity in rat SCs, thus influencing iron and lactate supplies for GCs, respectively. Incubation of rat SCs with U0126 or PD98059 both blocked phosphorylated-ERKinduced transferrin secretion and LDH catalytic activity $^{127}$. Galardo et al. further analyzed the intrinsic molecular mechanism behind these results ${ }^{128}$. There is a CRE- 
like sequence on the promoter of the transferrin encoding gene and a consensus CRE sequence on the promoter of the $L D H A$ gene in rat ${ }^{129-131}$. Treating rat SCs cultures with FGF-2 could increase phosphorylated CREB level, while PD98059 incubation inhibited FGF-2 stimulation on phosphorylated CREB, LDH A, and transferrin uprising level ${ }^{128}$. So CREB may act as the target of ERK1/2 signaling to regulate iron and lactate supplies in SCs.

\section{Pathways and potential clinical applications of abnormal spermatogenesis}

In patients with testicular tumor or infertility, abnormal activity of signaling pathways was observed, including the Wnt signaling pathway, the PI3k/Akt signaling pathway, etc $^{56,132-137}$. We had discussed of the TGF- $\beta / S m a d$, AMPK, and MAPK signaling pathways in SCs to regulate normal spermatogenesis. There are also clinical studies which revealed the relevance of the three pathways and abnormal spermatogenesis.

Infertility is an emerging worldwide public health issue $^{138,139}$. From 1990 to 2010, the number of infertile couples increased globally, and 48.5 million couples worldwide were disturbed ${ }^{140}$. Among them, approximately $20-70 \%$ of cases are owing to the male factor, and at least 30 million men worldwide being diagnosed with infertility according to statistic research in $2015^{141}$. Abnormal quality and insufficient quantity of sperm are the primary causes of male infertility, most of which are clinically manifested as oligozoospermia, asthenozoospermia, teratospermia, or azoospermia ${ }^{142}$. Azoospermia is classified as obstructive azoospermia and nonobstructive azoospermia $^{143}$, the latter of which is a major course for male infertility and affects $10-15 \%$ of infertile men ${ }^{144}$. The microarray analysis on testicular biopsy samples from azoospermic men detected over-activation of the MAPK signaling pathway in $\mathrm{SCs}^{145}$. For azoospermic patients, Sertoli cell-only syndrome affects $26.3-57.8 \%$ of them, whose testicular histology biopsies shows no germ cells and only Sertoli cells in the seminiferous tubules ${ }^{146}$. In testicular biopsies from nonobstructive azoospermia patients with Sertoli cell-only syndrome, BMP4, TGF- $\beta$ receptor II (TGF $\beta$ RII), and Smad2 are more highly expressed $^{57,70}$. As for the AMPK signaling pathway, studies in SCs of infertile humans are insufficient. However, number of pups per litter in SC- $\alpha 1 \mathrm{AMPK}$-cKO mice did decrease by $25 \%$, accompanied with disturbed cell junction dynamics ${ }^{86}$. Thus, for the purpose of elucidating the molecular basis and developing therapeutic options for azoospermia therapy, the causes of azoospermia deserve more attention in the future, especially from the perspective of the TGF- $\beta /$ Smad, AMPK, and MAPK signaling pathways in $\mathrm{SCs}^{147-150}$.

Testicular cancer is a common malignancy which can cause infertility and death in men ${ }^{151}$. In the year of 2018, the worldwide estimated number of new cases of testicular cancer at all ages reached 71,105 according to International Agency for Research on Cancer ${ }^{152}$. Testicular tumors can be classified into germ cell tumors, sex cord-stromal tumors, mixed germ cell/sex cord-stromal tumors, and lymphomas ${ }^{153}$. Sex cord-stromal tumors consist of Sertoli cell tumors, Leydig cell tumors, granulosa cell tumors, and unclassified tumors ${ }^{133,154}$. Testicular cancer development is potentially linked with the TGF- $\beta$ / Smad signaling pathway, especially when the BMP signaling SMADs (BR-SMADs) participate. Smad4, the CoSmad in the TGF- $\beta /$ Smad signaling pathway, may serve as a key mediator in Leydig cell adenomas. When Smad4 was conditionally knocked out in mouse Sertoli cells and Leydig cells, $87.5 \%$ of the mutant mice exhibited Leydig cell adenomas at 56-62 weeks of age ${ }^{64}$. After the BRSMADs (Smad1, 5) in mice SCs is deleted via tissuespecific ablation, all male Smad1/Smad5 KO mice (14 samples) developed Sertoli-Leydig tumors after 28 weeks of age with $100 \%$ metastases to lymph and peritonea, implicating the role of the BR-SMAD signaling pathway as a tumor suppressor in testis ${ }^{155}$.

\section{Conclusions and perspectives}

In present, the relationship between signaling pathways, infertility and tumorigenesis in SCs still remains unknown. However, various hormones, cytokines or proteins have been indicated to express differently in SCs if abnormal spermatogenesis occurs ${ }^{156}$. For instance, FSH suppresses Sertoli cell tumor progression during the 1st or 2nd week after birth, which is the first wave of spermatogenesis in inhibin $\alpha-\mathrm{KO}$ mice ${ }^{157}$. Since these signaling molecules are often involved in multiple signaling pathways in SCs or regulated by various signaling pathways ${ }^{158,159}$, identifying the determining signaling pathway that controls abnormal spermatogenesis is the first step to study the causes of abnormal spermatogenesis, progression of testicular cancer, and infertility ${ }^{160}$. These basic researches may facilitate diagnostics and therapeutics for testicular cancer and infertility, as well as development of targeted drugs, and all these advances will reduce cancer mortality and infertility morbidity in the future.

\section{Acknowledgements \\ The authors are grateful to all members of the Sperm Laboratory in Zhejiang University for their valuable discussion. This study was supported by the National Natural Science Foundation of China (No. 41776144 and No. 31572603).}

Author contributions

F.-D.N, S.-L.H., and W.-X.Y. conceived of and authored the paper.

Conflict of interest

The authors declare that they have no conflict of interest. 


\section{Publisher's note}

Springer Nature remains neutral with regard to jurisdictional claims in

published maps and institutional affiliations.

Received: 5 May 2019 Revised: 13 June 2019 Accepted: 17 June 2019 Published online: 17 July 2019

\section{References}

1. Wong, C. H. \& Cheng, C. Y. Mitogen-activated protein kinases, adherens junction dynamics, and spermatogenesis: a review of recent data. Dev. Biol. 286, 1-15 (2005)

2. Sharma, S., Hanukoglu, A. \& Hanukoglu, I. Localization of epithelial sodium channel (ENaC) and CFTR in the germinal epithelium of the testis, Sertoli cells, and spermatozoa. J. Mol. Histol. 49, 195-208 (2018).

3. $\mathrm{Hu}, \mathrm{K}$. Zhang, J. \& Liang, M. LnCRNA AK015322 promotes proliferation of spermatogonial stem cell C18-4 by acting as a decoy for microRNA-19b-3p. Vitr. Cell. Dev. Biol. Anim. 53, 277-284 (2017).

4. Wong, C. H. et al. Regulation of ectoplasmic specialization dynamics in the seminiferous epithelium by focal adhesion-associated proteins in testosterone-suppressed rat testes. Endocrinology 146, 1192-1204 (2005).

5. Zheng, B. et al. Cellular nucleic acid-binding protein is vital to testis development and spermatogenesis in mice. Reproduction 156, 59-69 (2018).

6. Xiao, X., Mruk, D. D. \& Cheng, C. Y. Intercellular adhesion molecules (ICAMs) and spermatogenesis. Hum. Reprod. Update 19, 167-186 (2013).

7. Mok, K. W., Mruk, D. D. \& Cheng, C. Y. rpS6 regulates blood-testis barrier dynamics through Akt-mediated effects on MMP-9. J. Cell Sci. 127, 4870-4882 (2014).

8. Stanton, P. G. Regulation of the blood-testis barrier. Semin. Cell Dev. Biol. 59 166-173 (2016).

9. Adams, A., Sriram, A. \& Wayne Vogl, A. Internalization of intact intercellular junctions in the testis by clathrin/actin-mediated endocytic structures: tubulobulbar complexes. Anat. Rec. 301, 2080-2085 (2018).

10. Ahmed, N. et al. Characterization of inter-Sertoli cell tight and gap junctions in the testis of turtle: Protect the developing germ cells from an immune response. Microb. Pathog. 123, 60-67 (2018).

11. Jiang, F. X. \& Short, R. V. Male germ cell transplantation in rats: apparent synchronization of spermatogenesis between host and donor seminiferous epithelia. Int. J. Androl. 18, 326-330 (1995).

12. Van Haaster, L. H. \& De Rooij, D. G. Partial synchronization of spermatogenesis in the immature Djungarian hamster, but not in the immature Wistar rat. J. Reprod. Fertil. 101, 321-326 (1994)

13. Agrimson, K. S. et al. Characterizing the spermatogonial response to retinoic acid during the onset of spermatogenesis and following synchronization in the neonatal mouse testis. Biol. Reprod. 95, 81 (2016).

14. Mancuso, F. et al. Testosterone and FSH modulate Sertoli cell extracellular secretion: Proteomic analysis. Mol. Cell. Endocrinol. 476, 1-7 (2018).

15. Beardsley, A. \& O'Donnell, L. Characterization of normal spermiation and spermiation failure induced by hormone suppression in adult rats. Biol. Reprod. 68, 1299-1307 (2003)

16. Hai, Y. et al. The roles and regulation of Sertoli cells in fate determinations of spermatogonial stem cells and spermatogenesis. Semin. Cell Dev. Biol. 29, 66-75 (2014).

17. Shiraishi, K. \& Matsuyama, H. Gonadotoropin actions on spermatogenesis and hormonal therapies for spermatogenic disorders. Endocr. J. 64, 123-131 (2017).

18. Iliadou, P. K., Tsametis, C., Kaprara, A., Papadimas, I. \& Goulis, D. G. The Sertoli cell: novel clinical potentiality. Hormones 14, 504-514 (2015).

19. Crisostomo, L. et al. Molecular mechanisms and signaling pathways involved in the nutritional support of spermatogenesis by Sertoli cells. Methods Mol. Biol. 1748, 129-155 (2018).

20. Yin, J. et al. Regulatory effects of autophagy on spermatogenesis. Biol. Reprod. 96, 525-530 (2017)

21. Ma, W. et al. Zika virus causes testis damage and leads to male infertility in mice. Cell 167, 1511-1524 (2016).

22. Wang, X. X. et al. Altered protein prenylation in Sertoli cells is associated with adult infertility resulting from childhood mumps infection. J. Exp. Med. 210, 1559-1574 (2013).

23. Kaur, G., Thompson, L. A. \& Dufour, J. M. Sertoli cells-immunological sentinels of spermatogenesis. Semin. Cell Dev. Biol. 30, 36-44 (2014).
24. Siemann, D. N., Strange, D. P., Maharaj, P. N., Shi, P. Y. \& Verma, S. Zika virus infects human sertoli cells and modulates the integrity of the in vitro bloodtestis barrier model. J. Virol. 91, e00623-17 (2017).

25. Yefimova, M. G. et al. Phagocytosis by Sertoli cells: analysis of main phagocytosis steps by confocal and electron microscopy. Methods Mol. Biol. 1748, 85-101 (2018).

26. Wei, $\mathrm{X}$. et al. B7-H3 promoted proliferation of mouse spermatogonial stem cells via the PI3K signaling pathway. Oncotarget 9, 1542-1552 (2018).

27. Lie, P. P., Cheng, C. Y. \& Mruk, D. D. Signalling pathways regulating the bloodtestis barrier. Int. J. Biochem. Cell Biol. 45, 621-625 (2013).

28. Chen, S. R. \& Liu, Y. X. Regulation of spermatogonial stem cell self-renewal and spermatocyte meiosis by Sertoli cell signaling. Reproduction 149, R159-167 (2015).

29. Boj, M., Chauvigne, F., Zapater, C. \& Cerda, J. Gonadotropin-activated androgen-dependent and independent pathways regulate aquaporin expression during teleost (Sparus aurata) spermatogenesis. PLOS ONE 10, e0142512 (2015).

30. Deng, Q. et al. Vesicle-associated membrane protein-associated protein a is involved in androgen receptor trafficking in mouse Sertoli cells. Int. J. Endocrinol. 2018, 4537214 (2018)

31. Zhang, J. J. et al. Identification of microRNAs for regulating adenosine monophosphate-activated prot-ein kinase expression in immature boar Sertoli cells in vitro. Mol. Reprod. Dev. 86, 450-464 (2019).

32. Santos, N. C. \& Kim, K. H. Activity of retinoic acid receptor-alpha is directly regulated at its protein kinase $A$ sites in response to follicle-stimulating hormone signaling. Endocrinology 151, 2361-2372 (2010).

33. Sen Sharma, S., Vats, A. \& Majumdar, S. Regulation of Hippo pathway components by FSH in testis. Reprod. Biol. 19, 61-66 (2019).

34. Levasseur, A., Paquet, M., Boerboom, D. \& Boyer, A. Yes-associated protein and $\mathrm{WW}$-containing transcription regulator 1 regulate the expression of sexdetermining genes in Sertoli cells, but their inactivation does not cause sex reversal. Biol. Reprod. 97, 162-175 (2017).

35. Siu, M. K., Wong, C. H., Lee, W. M. \& Cheng, C. Y. Sertoli-germ cell anchoring junction dynamics in the testis are regulated by an interplay of lipid and protein kinases. J. Biol. Chem. 280, 25029-25047 (2005).

36. Kanzaki, M. \& Morris, P. L. Identification and regulation of testicular interferongamma (IFNgamma) receptor subunits: IFNgamma enhances interferon regulatory factor-1 and interleukin-1 $\beta$ converting enzyme expression. Endocrinology 139, 2636-2644 (1998).

37. Jenab, S. \& Morris, P. L. Transcriptional regulation of Sertoli cell immediate early genes by interleukin-6 and interferon-gamma is mediated through phosphorylation of STAT-3 and STAT-1 proteins. Endocrinology 138, 2740-2746 (1997).

38. Ye, L. et al. Toxic effects of $\mathrm{TiO}_{2}$ nanoparticles in primary cultured rat sertoli cells are mediated via a dysregulated $\mathrm{Ca}^{2+} / \mathrm{PKC} / \mathrm{p} 38$ MAPK/NF-KB cascade. J. Biomed. Mater. Res. A 105, 1374-1382 (2018).

39. Zheng, W. et al. Zearalenone altered the cytoskeletal structure via ER stressautophagy-oxidative stress pathway in mouse TM4 Sertoli cells. Sci. Rep. 8, 3320 (2018).

40. Lei, T. et al. Galectin-1 enhances TNFa-induced inflammatory responses in Sertoli cells through activation of MAPK signalling. Sci. Rep. 8, 3741 (2018).

41. Wang, Y. et al. Triptolide induces Sertoli cell apoptosis in mice via ROS/JNKdependent activation of the mitochondrial pathway and inhibition of Nrf2mediated antioxidant response. Acta Pharmacol. Sin. 39, 311-327 (2018).

42. Qi, S. et al. BPA-induced apoptosis of rat Sertoli cells through Fas/FasL and JNKs/p38 MAPK pathways. Reprod. Toxicol. 50, 108-116 (2014).

43. Zhuang, M. et al. Reelin regulates male mouse reproductive capacity via the sertoli cells. J. Cell. Biochem. https://doi.org/10.1002/jcb.26824 (2018).

44. Mancuso, F. et al. Acute effects of lead on porcine neonatal Sertoli cells in vitro. Toxicol. Vitr. 48, 45-52 (2018).

45. Adegoke, E. O. et al. Microcystin-leucine arginine (MC-LR) induced inflammatory response in bovine sertoli cell via TLR4/NF-kB signaling pathway. Environ. Toxicol. Pharmacol. 63, 115-126 (2018).

46. Chen, Y., Wang, J., Pan, C., Li, D. \& Han, X. Microcystin-leucine-arginine causes blood-testis barrier disruption and degradation of occludin mediated by matrix metalloproteinase-8. Cell. Mol. Life Sci. 75, 1117-1132 (2018).

47. Li, L., Li, C. M., Wu, J., Huang, S. \& Wang, G. L. Heat shock protein 32/heme oxygenase-1 protects mouse Sertoli cells from hyperthermia-induced apoptosis by $\mathrm{CO}$ activation of SGC signalling pathways. Cell Bio. Int. $\mathbf{3 8}$ 64-71 (2014). 
48. Lee, N. P. \& Cheng, C. Y. Regulation of Sertoli cell tight junction dynamics in the rat testis via the nitric oxide synthase/soluble guanylate cyclase $/ 3^{\prime}, 5^{\prime}$ cyclic guanosine monophosphate/protein kinase $\mathrm{G}$ signaling pathway: an in vitro study. Endocrinology 144, 3114-3129 (2003).

49. Dirami, G., Ravindranath, N., Achi, M. V. \& Dym, M. Expression of Notch pathway components in spermatogonia and Sertoli cells of neonatal mice. J. Androl. 22, 944-952 (2001).

50. Khan, S. A., Ndjountche, L., Pratchard, L., Spicer, L. J. \& Davis, J. S. Folliclestimulating hormone amplifies insulin-like growth factor I-mediated activation of AKT/protein kinase B signaling in immature rat Sertoli cells. Endocrinology 143, 2259-2267 (2002)

51. Meroni, S. B., Riera, M. F., Pellizzari, E. H. \& Cigorraga, S. B. Regulation of rat Sertoli cell function by FSH: possible role of phosphatidylinositol 3-kinase/ protein kinase B pathway. J. Endocrinol. 174, 195-204 (2002).

52. La Sala, G. et al. Modulation of Dhh signaling and altered Sertoli cell function in mice lacking the GPR37-prosaposin receptor. FASEB J. 29, 2059-2069 (2015).

53. Sarraj, M. A. et al. Expression of Wsb2 in the developing and adult mouse testis. Reproduction 133, 753-761 (2007).

54. Itman, $C$. et al. Developmentally regulated SMAD2 and SMAD3 utilization directs activin signaling outcomes. Dev. Dyn. 238, 1688-1700 (2009).

55. Lu, N. et al. Loss of vascular endothelial growth factor A (VEGFA) isoforms in the testes of male mice causes subfertility, reduces sperm numbers, and alters expression of genes that regulate undifferentiated spermatogonia. Endocrinology 154, 4790-4802 (2013).

56. Wang, X. N. et al. The Wilms tumor gene, Wt1, is critical for mouse spermatogenesis via regulation of sertoli cell polarity and is associated with nonobstructive azoospermia in humans. PLoS Genet. 9, e1003645 (2013).

57. Sun, T., Xin, Z., Jin, Z., Wu, Y. \& Gong, Y. Effect of TGF- $\beta / S m a d$ signaling on sertoli cell and possible mechanism related to complete sertoli cell-only syndrome. Mol. Cell. Biochem. 319, 1-7 (2008).

58. Hao, X. X. et al. Selective deletion of Smad4 in postnatal germ cells does not affect spermatogenesis or fertility in mice. Mol. Reprod. Dev. 83, 615-623 (2016)

59. Young, J. C., Wakitani, S. \& Loveland, K. L. TGF- $\beta$ superfamily signaling in testis formation and early male germline development. Semin. Cell Dev. Biol. 45 94-103 (2015).

60. Itman, C. \& Loveland, K. L. SMAD expression in the testis: an insight into BMP regulation of spermatogenesis. Dev. Dyn. 237, 97-111 (2008).

61. Mendis, S. H., Meachem, S. J., Sarraj, M. A. \& Loveland, K. L. Activin A balances Sertoli and germ cell proliferation in the fetal mouse testis. Biol. Reprod. $\mathbf{8 4}$ 379-391 (2011).

62. Zhang, X. J., Wen, X. X., Zhao, L. \& He, J. P. Immunolocalization of Smad4 protein in the testis of domestic fowl (Gallus domesticus) during postnatal development. Acta Histochem. 114, 429-433 (2012).

63. Xu, J., Beyer, A. R., Walker, W. H. \& McGee, E. A. Developmental and stagespecific expression of Smad2 and Smad3 in rat testis. J. Androl. 24, 192-200 (2003).

64. Archambeault, D. R. \& Yao, H. H. Loss of smad4 in Sertoli and Leydig cells leads to testicular dysgenesis and hemorrhagic tumor formation in mice. Biol. Reprod. 90, 62 (2014)

65. Wijayarathna, R. \& de Kretser, D. M. Activins in reproductive biology and beyond. Hum. Reprod. Update 22, 342-357 (2016).

66. Fragale, A., Puglisi, R., Morena, A. R., Stefanini, M. \& Boitani, C. Agedependent activin receptor expression pinpoints activin $\mathrm{A}$ as a physiological regulator of rat Sertoli cell proliferation. Mol. Hum. Reprod. 7, 1107-1114 (2001)

67. Itman, C. et al. Smad3 dosage determines androgen responsiveness and sets the pace of postnatal testis development. Endocrinology 152, 2076-2089 (2011)

68. Pellegrini, M., Grimaldi, P., Rossi, P., Geremia, R. \& Dolci, S. Developmenta expression of BMP4/ALK3/SMAD5 signaling pathway in the mouse testis: a potential role of BMP4 in spermatogonia differentiation. J. Cell Sci. 116 3363-3372 (2003).

69. Yang, Y. et al. BMP4 Cooperates with Retinoic Acid to Induce the Expression of Differentiation Markers in Cultured Mouse Spermatogonia. Stem Cells Int. 2016, 9536192 (2016).

70. Hai, Y. et al. BMP4 promotes human Sertoli cell proliferation via Smad1/5 and ID2/3 pathway and its abnormality is associated with azoospermia. Discov. Med. 19, 311-325 (2015).
71. Wang, H. et al. BMP6 Regulates Proliferation and Apoptosis of Human Sertoli Cells Via Smad2/3 and Cyclin D1 Pathway and DACH1 and TFAP2A Activation. Sci. Rep. 7, 45298 (2017).

72. Cartier-Michaud, A. et al. Genetic, structural, and chemical insights into the dual function of GRASP55 in germ cell Golgi remodeling and JAM-C polarized localization during spermatogenesis. PLoS Genet. 13, e1006803 (2017)

73. Shao, M., Ghosh, A., Cooke, V. G., Naik, U. P. \& Martin-DeLeon, P. A. JAM-A is present in mammalian spermatozoa where it is essential for normal motility. Dev. Biol. 313, 246-255 (2008)

74. Wang, Y. \& Lui, W. Y. Opposite effects of interleukin-1a and transforming growth factor- $\beta 2$ induce stage-specific regulation of junctional adhesion molecule-B gene in Sertoli cells. Endocrinology 150, 2404-2412 (2009).

75. Zhang, X. \& Lui, W. Y. Transforming growth factor- $\beta 3$ regulates cell junction restructuring via MAPK-mediated mRNA destabilization and Smaddependent protein degradation of junctional adhesion molecule B (JAMB). Biochim. Biophys. Acta 1849, 601-611 (2015).

76. Lui, W. Y., Wong, E. W., Guan, Y. \& Lee, W. M. Dual transcriptional control of claudin-11 via an overlapping GATA/NF-Y motif: positive regulation through the interaction of GATA, NF-YA, and CREB and negative regulation through the interaction of Smad, HDAC1, and mSin3A. J. Cell. Physiol. 211, 638-648 (2007)

77. Tanaka, M., Chiba, K., Okada, K. \& Fujisawa, M. Effect of mirabegron on tight junction molecules in primary cultured rat Sertoli cells. Preprint at https://doi. org/10.1111/and.13241 (2019)

78. Li, L. et al. Cell polarity, cell adhesion, and spermatogenesis: role of cytoskeletons. FroooRes. 6, 1565 (2017)

79. Pan, J. et al. Expression of claudin11 in a rat model of varicocele and its effects on the bloodtestis barrier. Mol. Med. Rep. 18, 5647-5651 (2018).

80. Nicholls, P. K., Harrison, C. A., Gilchrist, R. B., Farnworth, P. G. \& Stanton, P. G. Growth differentiation factor 9 is a germ cell regulator of Sertoli cell function. Endocrinology 150, 2481-2490 (2009).

81. Zhao, L. et al. Expression of growth differentiation factor 9 (GDF9) and its receptor in adult cat testis. Acta Histochem. 113, 771-776 (2011)

82. Guo, O. Y., Gao, Z. Z., Zhao, L., He, J. P. \& Dong, C. S. Expression of growth differentiation factor 9 (GDF9), ALK5, and claudin-11 in adult alpaca testis. Acta Histochem. 115, 16-21 (2013).

83. Galardo, M. N., Riera, M. F., Pellizzari, E. H., Cigorraga, S. B. \& Meroni, S. B. The AMP-activated protein kinase activator, 5-aminoimidazole-4-carboxamide-1b-D-ribonucleoside, regulates lactate production in rat Sertoli cells. J. Mol. Endocrinol. 39, 279-288 (2007).

84. Petricca, S. et al. Tebuconazole and Econazole act synergistically in mediating mitochondrial stress, e-nergy imbalance and sequential activation of autophagy and apoptosis in mouse Sertoli TM4 cells: possible role of AMPK ULK1 axis. Preprint at https://doi.org/10.1093/toxsci/kfz031/5303844 (2019).

85. Tartarin, P. et al. Inactivation of AMPKa1 induces asthenozoospermia and alters spermatozoa morphology. Endocrinology 153, 3468-3481 (2012).

86. Bertoldo, M. J. et al. Specific deletion of AMP-activated protein kinase (a1AMPK) in mouse Sertoli cells modifies germ cell quality. Mol. Cell. Endocrinol. 423, 96-112 (2016).

87. Kishimoto, A et al. Immunohistochemical localization of GLUT3, MCT1, and $M C T 2$ in the testes of mice and rats: the use of different energy sources in spermatogenesis. Biomed. Res. 36, 225-234 (2015).

88. Brauchi, S. et al. Kinetics, molecular basis, and differentiation of L-lactate transport in spermatogenic cells. Am. J. Physiol. Cell Physiol. 288, C523-534 (2005)

89. Rato, L. et al. Metabolic modulation induced by oestradiol and DHT in immature rat Sertoli cells cultured in vitro. Biosci. Rep. 32, 61-69 (2012).

90. Nakai, M., Chen, L. \& Nowak, R. A. Tissue distribution of basigin and monocarboxylate transporter 1 in the adult male mouse: a study using the wildtype and basigin gene knockout mice. Anat. Rec. A. Discov. Mol. Cell. Evol. Biol. 288, 527-535 (2006)

91. Galardo, M. N. et al. Adenosine regulates Sertoli cell function by activating AMPK. Mol. Cell. Endocrinol. 330, 49-58 (2010).

92. Riera, M. F., Galardo, M. N., Pellizzari, E. H., Meroni, S. B. \& Cigorraga, S. B. Molecular mechanisms involved in Sertoli cell adaptation to glucose deprivation. Am. J. Physiol. Endocrinol. Metab. 297, E907-914 (2009).

93. Kokk, K. et al. Expression of insulin receptor substrates 1-3, glucose transporters GLUT-1-4, signal regulatory protein 1a, phosphatidylinositol 3-kinase and protein kinase $B$ at the protein level in the human testis. Anat. Sci. Int. $\mathbf{8 0}$ 91-96 (2005). 
94. Kokk, K. et al. Expression of insulin signaling transmitters and glucose transporters at the protein level in the rat testis. Ann. N. Y. Acad. Sci. 1095 262-273 (2007).

95. Nguyen, T. M. Impact of 5'-amp-activated Protein Kinase on Male Gonad and Spermatozoa Functions. Front. Cell Dev. Biol. 5, 25 (2017).

96. Yang, W. R. et al. Role of AMPK in the expression of tight junction proteins in heat-treated porcine Sertoli cells. Theriogenology 121, 42-52 (2018).

97. Li, W. et al. The proteasome inhibitor bortezomib induces testicular toxicity by upregulation of oxidative stress, AMP-activated protein kinase (AMPK) activation and deregulation of germ cell development in adult murine testis. Toxicol. Appl. Pharmacol. 285, 98-109 (2015).

98. Zheng, W. L. et al. ROS-Mediated Cell Cycle Arrest and Apoptosis Induced by Zearalenone in Mouse Sertoli Cells via ER Stress and the ATP/AMPK Pathway. Toxins (Basel) 10, 24 (2018).

99. Riera, M. F. et al. Signal transduction pathways in FSH regulation of rat Sertoli cell proliferation. Am. J. Physiol. Endocrinol. Metab. 302, E914-E923 (2012).

100. Jiao, Z. J., Yi, W., Rong, Y. W., Kee, J. D. \& Zhong, W. X. MicroRNA-1285 Regulates $17 \beta$-Estradiol-Inhibited Immature Boar Sertoli Cell Proliferation via Adenosine Monophosphate-Activated Protein Kinase Activation. Endocrinology 156, 4059-4070 (2015)

101. Gautam, M., Bhattacharya, I., Rai, U. \& Majumdar, S. S. Hormone induced differential transcriptome analysis of Sertoli cells during postnatal maturation of rat testes. PloS ONE 13, e0191201 (2018).

102. Lui, W. Y., Lee, W. M. \& Cheng, C. Y. Transforming growth factor $\beta 3$ regulates the dynamics of Sertoli cell tight junctions via the p38 mitogen-activated protein kinase pathway. Biol. Reprod. 68, 1597-1612 (2003).

103. Lui, W. Y., Lee, W. M. \& Cheng, C. Y. TGF- $\beta$ s: their role in testicular function and Sertoli cell tight junction dynamics. Int. J. Androl. 26, 147-160 (2003).

104. Xia, W., Mruk, D. D., Lee, W. M. \& Cheng, C. Y. Differential interactions between transforming growth factor- $\beta 3 / \mathrm{T} \beta \mathrm{R} 1, \mathrm{TAB} 1$, and CD2AP disrupt blood-testis barrier and Sertoli-germ cell adhesion. J. Biol. Chem. 281 16799-16813 (2006)

105. Wong, C. H., Mruk, D. D., Lui, W. Y. \& Cheng, C. Y. Regulation of blood-testis barrier dynamics: an in vivo study. J. Cell Sci. 117, 783-798 (2004).

106. Li, M. W. et al. Tumor necrosis factor a reversibly disrupts the blood-testis barrier and impairs Sertoli-germ cell adhesion in the seminiferous epithelium of adult rat testes. J. Endocrinol. 190, 313-329 (2006).

107. Xiao, X., Cheng, C. Y. \& Mruk, D. D. Intercellular adhesion molecule-1 is a regulator of blood-testis barrier function. J. Cell Sci. 125, 5677-5689 (2012).

108. De Cesaris, P. et al. Activation of Jun N-terminal kinase/stress-activated protein kinase pathway by tumor necrosis factor a leads to intercellular adhesion molecule-1 expression. J. Biol. Chem. 274, 28978-28982 (1999).

109. De Cesaris, P. et al. Tumor necrosis factor-a induces interleukin-6 production and integrin ligand expression by distinct transduction pathways. J. Biol. Chem. 273, 7566-7571 (1998)

110. Mruk, D., Zhu, L. J., Silvestrini, B., Lee, W. M. \& Cheng, C. Y. Interactions of proteases and protease inhibitors in Sertoli-germ cell cocultures preceding the formation of specialized Sertoli-germ cell junctions in vitro. J. Androl. 18, 612-622 (1997).

111. Wong, C. H., Mruk, D. D., Siu, M. K. \& Cheng, C. Y. Blood-testis barrier dynamics are regulated by $\mathrm{a}_{2}$-macroglobulin via the $\mathrm{c}$-Jun $\mathrm{N}$-terminal protein kinase pathway. Endocrinology 146, 1893-1908 (2005)

112. Yamamoto, $\mathrm{H}$. et al. Detection of spatial localization of Hst-1/Fgf-4 gene expression in brain and testis from adult mice. Oncogene 19, 3805-3810 (2000)

113. Hirai, K. et al. HST-1/FGF-4 protects male germ cells from apoptosis under heat-stress condition. Exp. Cell Res. 294, 77-85 (2004).

114. Jiang, $X$. et al. The roles of fibroblast growth factors in the testicular development and tumor. J. Diabetes Res. 2013, 489095 (2013).

115. Godet, M., Sabido, O., Gilleron, J. \& Durand, P. Meiotic progression of rat spermatocytes requires mitogen-activated protein kinases of Sertoli cells and close contacts between the germ cells and the Sertoli cells. Dev. Biol. $\mathbf{3 1 5}$ 173-188 (2008)

116. Braydich-Stolle, L., Nolan, C., Dym, M. \& Hofmann, M. C. Role of glial cell linederived neurotrophic factor in germ-line stem cell fate. Ann. N. Y. Acad. Sci. 1061, 94-99 (2005)

117. Tanwar, P. S. et al. Constitutive WNT/beta-catenin signaling in murine Sertoli cells disrupts their differentiation and ability to support spermatogenesis. Biol. Reprod. 82, 422-432 (2010).

118. Lamberti, D. \& Vicini, E. Promoter analysis of the gene encoding GDNF in murine Sertoli cells. Mol. Cell. Endocrinol. 394, 105-114 (2014).
119. Garcia, T. X., DeFalco, T., Capel, B. \& Hofmann, M. C. Constitutive activation of NOTCH1 signaling in Sertoli cells causes gonocyte exit from quiescence. Dev. Biol. 377, 188-201 (2013)

120. Garcia, T. X. \& Hofmann, M. C. NOTCH signaling in Sertoli cells regulates gonocyte fate. Cell Cycle 12, 2538-2545 (2013).

121. Garcia, T. X., Farmaha, J. K. Kow, S. \& Hofmann, M. C. RBPJ in mouse Sertoli cells is required for proper regulation of the testis stem cell niche. Development 141, 4468-4478 (2014).

122. Garcia, T. X., Parekh, P., Gandhi, P., Sinha, K. \& Hofmann, M. C. The NOTCH Ligand JAG1 Regulates GDNF Expression in Sertoli Cells. Stem Cells Dev. 26 585-598 (2017).

123. Hasegawa, K., Namekawa, S. H. \& Saga, Y. MEK/ERK signaling directly and indirectly contributes to the cyclical self-renewal of spermatogonial stem cells. Stem Cells 31, 2517-2527 (2013).

124. Crepieux, P. et al. The ERK-dependent signalling is stage-specifically modulated by FSH, during primary Sertoli cell maturation. Oncogene 20, 4696-4709 (2001)

125. Yao, P. L. et al. Peroxisome Proliferator-activated Receptor-D (PPARD) Coordinates Mouse Spermatogenesis by Modulating Extracellular Signalregulated Kinase (ERK)-dependent Signaling. J. Biol. Chem. 290, 23416-23431 (2015).

126. Lucas, T. F., Amaral, L. S., Porto, C. S. \& Quintas, L. E. Na ${ }^{+} / K^{+}$-ATPase a1 isoform mediates ouabain-induced expression of cyclin D1 and proliferation of rat sertoli cells. Reproduction 144, 737-745 (2012).

127. Riera, M. F., Meroni, S. B., Pellizzari, E. H. \& Cigorraga, S. B. Assessment of the roles of mitogen-activated protein kinase and phosphatidyl inositol 3-kinase/ protein kinase $B$ pathways in the basic fibroblast growth factor regulation of Sertoli cell function. J. Mol. Endocrinol. 31, 279-289 (2003).

128. Galardo, M. N. et al. Different signal transduction pathways elicited by basic fibroblast growth factor and interleukin $1 \beta$ regulate CREB phosphorylation in Sertoli cells. J. Endocrinol. Invest. 36, 331-338 (2013).

129. Suire, S., Fontaine, I. \& Guillou, F. Follicle stimulating hormone (FSH) stimulates transferrin gene transcription in rat Sertoli cells: cis and trans-acting elements involved in FSH action via cyclic adenosine $3^{\prime}, 5^{\prime}$-monophosphate on the transferrin gene. Mol. Endocrinol. 9, 756-766 (1995).

130. Chaudhary, J. \& Skinner, M. K. E-box and cyclic adenosine monophosphate response elements are both required for follicle-stimulating hormoneinduced transferrin promoter activation in Sertoli cells. Endocrinology $\mathbf{1 4 0}$ 1262-1271 (1999).

131. Short, M. L. et al. Analysis of the rat lactate dehydrogenase A subunit gene promoter/regulatory region. Biochem. J. 304, 391-398 (1994).

132. Lombardi, A. P. et al. Physiopathological aspects of the Wnt/B-catenin signaling pathway in the male reproductive system. Spermatogenesis $\mathbf{3}$, e23181 (2013).

133. Chang, H., Guillou, F., Taketo, M. M. \& Behringer, R. R. Overactive beta-catenin signaling causes testicular sertoli cell tumor development in the mouse. Biol. Reprod. 81, 842-849 (2009).

134. Tanwar, P. S., Commandeur, A. E., Zhang, L., Taketo, M. M. \& Teixeira, J. M. The Mullerian inhibiting substance type 2 receptor suppresses tumorigenesis in testes with sustained $\beta$-catenin signaling. Carcinogenesis 33, 2351-2361 (2012).

135. Long, L. et al. Hyperglycemia induced testicular damage in type 2 diabetes mellitus rats exhibiting microcirculation impairments associated with vascular endothelial growth factor decreased via PI3K Akt pathway. Oncotarget $\mathbf{9}$ 5321-5336 (2018)

136. Tabecka-Lonczynska, A. et al. Vascular endothelial growth factor (VEGF-A) and fibroblast growth factor (FGF-2) as potential regulators of seasonal reproductive processes in male European bison (Bison bonasus, Linnaeus 1758). Gen. Comp. Endocrinol. 263, 72-79 (2018).

137. Devi, L., Pothana, L. \& Goel, S. Dysregulation of angiogenesis-specific signalling in adult testis results in xenograft degeneration. Sci. Rep. 7, 2605 (2017).

138. Vander Borght, M. \& Wyns, C. Fertility and infertility: Definition and epidemiology. Clin. Biochem. 62, 2-10 (2018).

139. Krausz, C. \& Riera-Escamilla, A. Genetics of male infertility. Nat. Rev. Urol. 15 369-384 (2018).

140. Mascarenhas, M. N., Flaxman, S. R., Boerma, T., Vanderpoel, S. \& Stevens, G. A. National, regional, and global trends in infertility prevalence since 1990: a systematic analysis of 277 health surveys. PLoS Med. 9, e1001356 (2012).

141. Agarwal, A., Mulgund, A., Hamada, A. \& Chyatte, M. R. A unique view on male infertility around the globe. Reprod. Biol. Endocrinol. 13, 37 (2015). 
142. Hajder, M., Hajder, E. \& Husic, A. The Effects of Total Motile Sperm Count on Spontaneous Pregnancy Rate and Pregnancy After IUI Treatment in Couples with Male Factor and Unexplained Infertility. Med. Arch. 70, 39-43 (2016).

143. Steele, E. K., Lewis, S. E. \& McClure, N. Science versus clinical adventurism in treatment of azoospermia. Lancet 353, 516-517 (1999).

144. Esteves, S. C. Novel concepts in male factor infertility: clinical and laboratory perspectives. J. Assist. Reprod. Genet. 33, 1319-1335 (2016).

145. Spiess, A. N. et al. Cross-platform gene expression signature of human spermatogenic failure reveals inflammatory-like response. Hum. Reprod. 22, 2936-2946 (2007).

146. Abofoul-Azab, M. et al. Identification of Premeiotic, Meiotic, and Postmeiotic Cells in Testicular Biopsies Without Sperm from Sertoli Cell-Only Syndrome Patients. Int. J. Mol. Sci. 20, 470 (2019).

147. Shen, L. et al. Vitamin E and vitamin C attenuate Di-(2-ethylhexyl) phthalateinduced blood-testis barrier disruption by p38 MAPK in immature SD rats. Reprod. Toxicol. 81, 17-27 (2018).

148. Cannarella, R., Condorelli, R. A., La Vignera, S. \& Calogero, A. E. Effects of the insulin-like growth factor system on testicular differentiation and function: a review of the literature. Andrology 6, 3-9 (2018).

149. Wang, M. \& Su, P. The role of the Fas/FasL signaling pathway in environmental toxicant-induced testicular cell apoptosis: An update. Syst. Biol. Reprod. Med. 64, 93-102 (2018).

150. Miyamoto, T., Minase, G., Okabe, K., Ueda, H. \& Sengoku, K. Male infertility and its genetic causes. J. Obstet. Gynaecol. Res. 41, 1501-1505 (2015).

151. Sung, H., Siegel, R. L., Rosenberg, P. S. \& Jemal, A. Emerging cancer trends among young adults in the USA: analysis of a population-based cancer registry. Lancet Public Health 4, e137-e147 (2019).

152. International agency for research on cancer. Estimated number of new cases in 2018, worldwide, males, all ages. CANCER TODAY. http//gco.iarc.fr/today/ online-analysis-table? $\mathrm{v}=2018 \&$ mode $=$ cancer $\&$ mode_population $=$ continents\&population $=900 \&$ populations $=900 \&$ key $=$ asr $\&$ sex $=1 \&$ cancer $=$ $39 \&$ type $=0 \&$ statistic $=5 \&$ prevalence $=0 \&$ population_group $=0 \&$ ages_group $\% 5 \mathrm{~B} \% 5 \mathrm{D}=0 \&$ ages_group $\% 5 \mathrm{~B} \% 5 \mathrm{D}=17 \& \mathrm{nb}$ _items $=5 \&$ group_cancer $=$ 1\&include_nmsc $=1$ \&include_nmsc_other $=1$ (2018).

153. Feldman, D. R., Bosl, G. J., Sheinfeld, J. \& Motzer, R. J. Medical treatment of advanced testicular cancer. JAMA 299, 672-684 (2008).

154. Szarek, M. et al. Activin A target genes are differentially expressed between normal and neoplastic adult human testes: clues to gonocyte fate choice. Andrology 7, 31-41 (2019).

155. Pangas, S. A. et al. Conditional deletion of Smad1 and Smad5 in somatic cells of male and female gonads leads to metastatic tumor development in mice. Mol. Cell. Biol. 28, 248-257 (2008).

156. Meng, $X$. et al. Regulation of cell fate decision of undifferentiated spermatogonia by GDNF. Science 287, 1489-1493 (2000).

157. Haverfield, J. T. et al. Suppression of Sertoli cell tumour development during the first wave of spermatogenesis in inhibin a-deficient mice. Reprod. Fertil. Dev. 29, 609-620 (2017).

158. Hu, X. et al. Deletion of the tyrosine phosphatase Shp2 in Sertoli cells causes infertility in mice. Sci. Rep. 5, 12982 (2015).

159. Walker, W. H. \& Cheng, J. FSH and testosterone signaling in Sertoli cells. Reproduction 130, 15-28 (2005).
160. Rajpert-De Meyts, E., McGlynn, K. A., Okamoto, K., Jewett, M. A. \& Bokemeyer, C. Testicular germ cell tumours. Lancet 387, 1762-1774 (2016).

161. Kumar, A., Dumasia, K., Deshpande, S. \& Balasinor, N. H. Direct regulation of genes involved in sperm release by estrogen and androgen through their receptors and coregulators. J. Steroid Biochem. Mol. Biol. 171, 66-74 (2017).

162. Zhang, $H$. et al. Interleukin-6 disrupts blood-testis barrier through inhibiting protein degradation or activating phosphorylated ERK in Sertoli cells. Sci. Rep. 4, 4260 (2014).

163. Rossi, G. et al. Follicle-stimulating hormone activates fatty acid amide hydrolase by protein kinase $\mathrm{A}$ and aromatase-dependent pathways in mouse primary Sertoli cells. Endocrinology 148, 1431-1439 (2007)

164. Eto, K., Shiotsuki, M., Sakai, T. \& Abe, S. Nociceptin is upregulated by FSH signaling in Sertoli cells in murine testes. Biochem. Biophys. Res. Commun. 421, 678-683 (2012)

165. Eto, K. Nociceptin and meiosis during spermatogenesis in postnatal testes. Vitam. Horm. 97, 167-186 (2015).

166. Lucas, T. F. G., Lazari, M. F. M. \& Porto, C. S. Differential role of the estrogen receptors ESR1 and ESR2 on the regulation of proteins involved with proliferation and differentiation of Sertoli cells from 15-day-old rats. Mol. Cell. Endocrinol. 382, 84-96 (2014)

167. Yao, P. L., Lin, Y. C., Sawhney, P. \& Richburg, J. H. Transcriptional regulation of FasL expression and participation of sTNF-a in response to sertoli cell injury. J. Biol. Chem. 282, 5420-5431 (2007).

168. Yao, P. L., Lin, Y. C. \& Richburg, J. H. TNF alpha-mediated disruption of spermatogenesis in response to Sertoli cell injury in rodents is partially regulated by MMP2. Biol. Reprod. 80, 581-589 (2009).

169. Delfino, F. J., Boustead, J. N., Fix, C. \& Walker, W. H. NF-KB and TNF-a stimulate androgen receptor expression in Sertoli cells. Mol. Cell. Endocrinol. 201, 1-12 (2003).

170. Zhang, L. et al. Nuclear factor-kB activates transcription of the androgen receptor gene in Sertoli cells isolated from testes of adult rats. Endocrinology 145, 781-789 (2004)

171. Lee, N. P., Mruk, D. D., Wong, C. H. \& Cheng, C. Y. Regulation of Sertoligerm cell adherens junction dynamics in the testis via the nitric oxide synthase (NOS)/cGMP/protein kinase G (PRKG)/ $\beta$-catenin (CATNB) signaling pathway: an in vitro and in vivo study. Biol. Reprod. 73, 458-471 (2005).

172. Matzkin, M. E. et al. Exploring the cyclooxygenase 2 (COX2)/15d- $\Delta^{12,14} P G J_{2}$ system in hamster Sertoli cells: regulation by FSH/testosterone and relevance to glucose uptake. Gen. Comp. Endocrinol. 179, 254-264 (2012).

173. Rajamanickam, G. D., Kastelic, J. P. \& Thundathil, J. C. The ubiquitous isoform of $\mathrm{Na} / \mathrm{K}$-ATPase (ATP1A1) regulates junctional proteins, connexin 43 and claudin 11 via Src-EGFR-ERK1/2-CREB pathway in rat Sertoli cells. Biol. Reprod. 96, 456-468 (2017)

174. Sun, Y. et al. Thyroid hormone inhibits the proliferation of piglet Sertoli cell via PI3K signaling pathway. Theriogenology 83, 86-94 (2015).

175. Basu, S. et al. Defective Wnt3 expression by testicular Sertoli cells compromise male fertility. Cell Tissue Res. 371, 351-363 (2018).

176. Lopez, C. et al. Wnt/ $\beta$-catenin signaling enhances transcription of the CX43 gene in murine Sertoli cells. J. Cell. Biochem. 120, 6753-6762 (2019). 